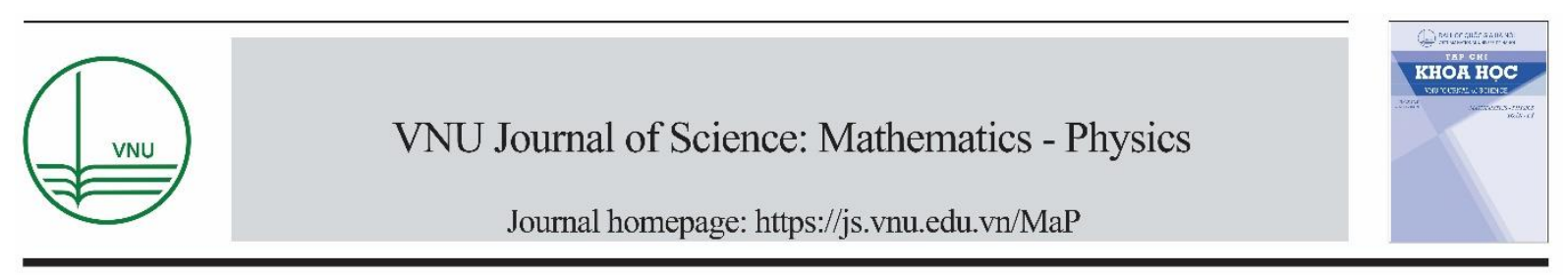

\title{
Molecular Dynamic Simulation of Large Model of Silica Liquid
}

\author{
Nguyen Thi Thanh $\mathrm{Ha}^{1, *}$, Phan Quan ${ }^{1}$, Tran Van Hong ${ }^{2}$, Le Van Vinh ${ }^{1}$ \\ ${ }^{1}$ Department of Computational Physics, Hanoi University of Science and Technology, Vietnam \\ ${ }^{2}$ Department of Physics, Thai Nguyen University of Education, Thai Nguyen, Vietnam
}

Received 04 October 2018

Revised 14 November 2018; Accepted 29 November 2018

\begin{abstract}
We perform a molecular dynamics simulation to study the microstructure and dynamical properties in large silica model at liquid state. The models consisting of 19998 atoms were constructed under a wide range of pressure $(0-20 \mathrm{GPa})$ and at $3500 \mathrm{~K}$ temperature. Structural characteristics were clarified through the pair radial distribution function (PRDF), the distribution of $\mathrm{SiO}_{\mathrm{x}}$ coordination units and network structure. The result shows that these liquids consist of identical units $\mathrm{SiO}_{4}, \mathrm{SiO}_{5}$ and $\mathrm{SiO}_{6}$ and have common partial $\mathrm{O}-\mathrm{Si}-\mathrm{O}$ angle distribution. Furthermore, the major change in the diffusion mechanism under pressure is also considered and discussed.
\end{abstract}

Keywords: Molecular dynamics, structure, coordination units, diffusion, network structure.

\section{Introduction}

Silica and silicate minerals (mixture of $\mathrm{SiO}_{2}$ and other metal oxides) play an important role in geosciences and technology. So, the complete knowledge of the structure and dynamical properties in silica and silicate under conditions of high pressure and temperature is quite necessary. The results of research studies will optimize the process of manufacturing new materials for intended use and controlling geological activities [1-4]. As we have known, the silicate glass- and meltstructures consists of $\mathrm{SiO}_{4}$ tetrahedra linking to each other form continuous random tetrahedral-network in three-dimensional space [5-7]. In pure silica glass and melt, each $\mathrm{SiO}_{4}$ tetrahedron connects to four other adjacent $\mathrm{SiO}_{4}$ tetrahedra via bridging-oxygen (BO). The addition of other oxides (such as $\mathrm{Na}_{2} \mathrm{O}$, $\mathrm{CaO}, \mathrm{MgO}$ or $\mathrm{PbO} \ldots)$ into pure silica $\left(\mathrm{SiO}_{2}\right)$ disrupts the basic silica network by breaking part of the $\mathrm{Si}-\mathrm{O}$ bonds, generating non-bridging oxygen (NBO). The percentage of NBOs in the system increases with the alkali content [8-9]. The detailed degree of mixing between $\mathrm{Si}-\mathrm{O}$ network and metal ions as well as the distribution of $\mathrm{BO}$ and $\mathrm{NBO}$ species yields insights into the atomic scale structure that govern

\footnotetext{
${ }^{*}$ Corresponding author: Tel.: 84-983012387.

Email: ha.nguyenthithanh1@ @ust.edu.vn

https//doi.org/ 10.25073/2588-1124/vnumap.4231
} 
the mechanical-physical-chemical properties of silicate glass system. The degree of polymerization depends on the ratio between the number of bridging oxygen (BO) and $\mathrm{SiO}_{4}$ tetrahedral units (the abundance of different $Q^{(\mathrm{n})}$ species, where $Q$ represents the $\mathrm{SiO}_{4}$ tetrahedron; $n$ is the number of $\mathrm{BO}$ ). The response of viscosity to pressure is found to be strikingly distinct between polymerized and simple liquid [10-11]. The degree of polymerization is also closely related to the diffusion of atoms in silicate. The neutron, X-ray diffraction (XRD) techniques, magic-angle spinning (MAS) nuclear magnetic resonance (NMR) [12-13] and simulation methods [14-15] have observed these phenomena. Liquid silica is a typical network forming system. Its structure consists of basic structural units $\mathrm{SiO}_{\mathrm{x}}(\mathrm{x}=4,5,6)$ and the $\mathrm{SiO}_{4}$ units is dominant at low pressure. When the liquid is compressed to smaller volume, the units $\mathrm{SiO}_{5}$ and $\mathrm{SiO}_{6}$ become prevalent. Due to its network-forming ability, the liquid silica exhibits a number of peculiar properties, which have been observed in both simulation and experiment. Namely, the compressibility of liquid silica in the interval of pressure up to $10 \mathrm{GPa}$ is substantially higher than that of quartz [16]. Moreover, anomalous behavior diffusion and spatially heterogeneous dynamics are also observed [17-18].

In our previous works, the micro-structure and dynamical properties in silica liquid also have been investigated via through the pair radial distribution function (PRDF), the distribution of $\mathrm{SiO}_{x}$ coordination units, the bond angle distribution and structure network. However, the research model has only 2000 atoms. To check the accuracy of previous research results and evaluate the effect of model size, we have conducted a $\mathrm{SiO}_{2}$ model consisting of 19998 atoms by mean of molecular dynamic simulation. This is a large model and quite difficult to build it. We will investigate the structural characteristic and coefficient diffusion in silica liquid under different pressure, compare with the experimental results and simulations. Moreover, the major change in the diffusion mechanism under pressure is also considered and discussed.

\section{Calculation}

We have prepared the model which consists of $6666 \mathrm{Si}$ and $13332 \mathrm{O}$ by means of MD simulation. In this paper, we simulate silica liquid with the BKS potential. The integration is performed using a velocity-Verlet algorithm with time step of $1.0 \mathrm{fs}$. The integration is performed using a velocity-Verlet algorithm with time step of $1.0 \mathrm{fs}$. Initial configuration of MD silica liquid model is constructed by randomly in simulation box and heating up to $6000 \mathrm{~K}$ to remove possible memory effects. Next, a long relaxation has been done in NPT ensemble (moles $(\mathrm{N})$, pressure $(\mathrm{P})$ and temperature $(\mathrm{T})$ are constant) to produce a model at $3500 \mathrm{~K}$ and upon ambient pressure. We obtain a sample at ambient pressure which is denoted to model M1. The model M1 has been compressed to different pressure $(5,10,15,20 \mathrm{GPa})$. In order to improve statistics, all quantities of considered structural data were calculated by averaging over the 5.000 configurations during the last simulation $\left(10^{5} \mathrm{MD}\right.$ steps). To observe the dynamical processes, two above models are relaxed in NVE ensemble (the system is isolated from changes in moles $(\mathrm{N})$, volume $(\mathrm{V})$ and energy $(\mathrm{E}))$ for a long time $\left(10^{6} \mathrm{MD}\right.$ steps).

\section{Results and discussion}

\subsection{Radial distribution function}

Firstly, we examine the structural characteristics of constructed models. The Fig.1 presents the PRDF of $\mathrm{Si}-\mathrm{Si}, \mathrm{Si}-\mathrm{O}$ and $\mathrm{O}-\mathrm{O}$ at different compressions. It can be seen that the first peak all atomic pairs decreases in amplitude and becomes broader under compression. The position of the first peak of 
$\mathrm{Si}-\mathrm{Si}$, and $\mathrm{O}-\mathrm{O}$ pairs decreases meanwhile $\mathrm{Si}-\mathrm{O}$ pairs, the position of the first peak of $\mathrm{Si}-\mathrm{O}$ increases. Moreover, the shift of the first peak of $g_{S i-O}(r)$ is the least and this indicates that the short-range order of silica liquid is not sensitive to the compression at pressures ranging from 0 to $20 \mathrm{GPa}$. The detail result is showed in Table 1. The characteristic of the PRDF is in good agreement with the reported data in refs. $[19,20]$



Fig 1. Radial distribution functions of $\mathrm{Si}-\mathrm{Si}, \mathrm{Si}-\mathrm{O}$, and $\mathrm{O}-\mathrm{O}$ pairs at different pressures.

\subsection{Coordination units}

The structure of $\mathrm{SiO}_{2}$ liquid consists of structural units $\mathrm{SiO}_{\mathrm{x}}(\mathrm{x}=4,5,6)$ and $\mathrm{OSi}_{\mathrm{y}}(\mathrm{y}=2,3)$. Figure 2 (a) distribution of coordination units $\mathrm{SiO}_{4}$ in the model. In which, only coordination units $\mathrm{SiO}_{4}$ are drawn, while the others are removed. Similarly, Figure 2 (b)-(c) shows the distributions of coordination units $\mathrm{SiO}_{5}, \mathrm{SiO}_{6}$. The detail dependence of the fraction of coordination units $\mathrm{SiO}_{\mathrm{x}}$ and $\mathrm{OSi}_{\mathrm{y}}$ on pressure was presented in Table 2. 
Table 1. Structural characteristics of $\mathrm{SiO}_{2}$ liquid, $r_{l k}$ is positions of first peak of PRDF, $g_{l k}$ is high of first peak of PRDF

\begin{tabular}{lllllll}
\hline Model & $0 \mathrm{GPa}$ & $5 \mathrm{GPa}$ & $10 \mathrm{GPa}$ & $15 \mathrm{GPa}$ & $20 \mathrm{GPa}$ & $\operatorname{Ref}[19,20]$ \\
\hline $\mathrm{r}_{\mathrm{Si}-\mathrm{Si}},[\AA]$ & 3.16 & 3.12 & 3.14 & 3.12 & 3.12 & 3.12 \\
$\mathrm{r}_{\mathrm{Si}-\mathrm{O}},[\AA]$ & 1.62 & 1.62 & 1.62 & 1.64 & 1.62 & 1.62 \\
$\mathrm{r}_{\mathrm{O}-\mathrm{O},},[\AA]$ & 2.64 & 2.52 & 2.56 & 2.5 & 2.48 & 2.65 \\
$\mathrm{~g}_{\mathrm{Si}-\mathrm{Si}}$ & 2.86 & 2.67 & 2.45 & 2.37 & 2.35 & - \\
$\mathrm{g}_{\mathrm{Si}-\mathrm{O}}$ & 8.62 & 7.14 & 6.19 & 5.54 & 5.26 & - \\
$\mathrm{g}_{\mathrm{O}-\mathrm{O}}$ & 2.72 & 2.44 & 2.37 & 2.39 & 2.37 & - \\
\hline
\end{tabular}

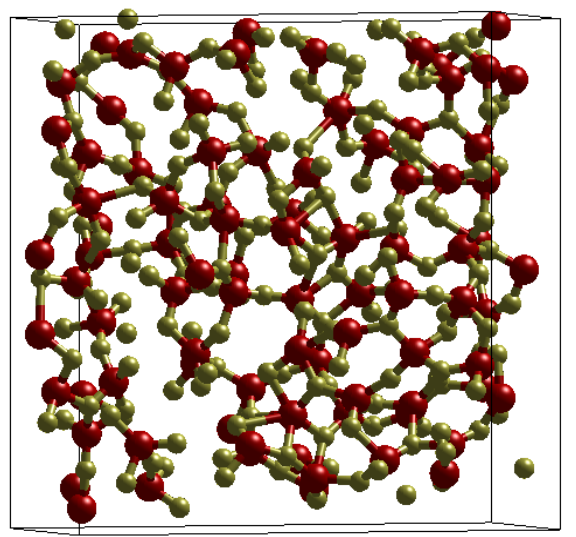

(a)



(b)



(c)

Fig 2. Snapshots of coordination unit distributions $\mathrm{SiO} x$ in model at ambient pressure: (a) distribution of coordination units $\mathrm{SiO}_{4}$, (b) distribution of coordination units $\mathrm{SiO}_{5}$, (c) distribution of coordination units $\mathrm{SiO}_{6}$.

It has been seen that the number of $\mathrm{SiO}_{4}$ and $\mathrm{OSi}_{2}$ unit is domain at ambient. When increasing pressure, the fraction of $\mathrm{SiO}_{5}$ and $\mathrm{SiO}_{6}$ increases meanwhile fraction of $\mathrm{OSi}_{3}$ and $\mathrm{OSi}_{2}$ also increases. This demonstrates that a transition from $\mathrm{SiO}_{4}$ to $\mathrm{SiO}_{5}$ or $\mathrm{SiO}_{6}$ should be accompanied by a transition 
from $\mathrm{OSi}_{2}$ to $\mathrm{OSi}_{3}$. It means that increasing pressure, there is a transformation from four-fold coordination $\left(\mathrm{SiO}_{4}\right)$ to five- and six-fold coordination $\left(\mathrm{SiO}_{5}\right.$ and $\left.\mathrm{SiO}_{6}\right)$.

Table 2. The percentage fraction of the coordination units in silica liquid at different pressure

\begin{tabular}{llllll}
\hline Model & 0GPa & $\mathbf{5 ~ G P a}$ & 10 GPa & 15 GPa & 20 GPa \\
\hline $\mathrm{SiO}_{4}$ & 93.94 & 77.26 & 59.89 & 44.89 & 35.69 \\
$\mathrm{SiO}_{5}$ & 3.90 & 19.34 & 34.65 & 45.66 & 50.13 \\
$\mathrm{SiO}_{6}$ & 0.03 & 0.79 & 3.51 & 8.14 & 12.77 \\
$\mathrm{OSi}_{2}$ & 95.72 & 86.26 & 75.53 & 66.01 & 59.95 \\
$\mathrm{OSi}_{3}$ & 4.28 & 13.74 & 24.47 & 33.99 & 40.05 \\
\hline
\end{tabular}

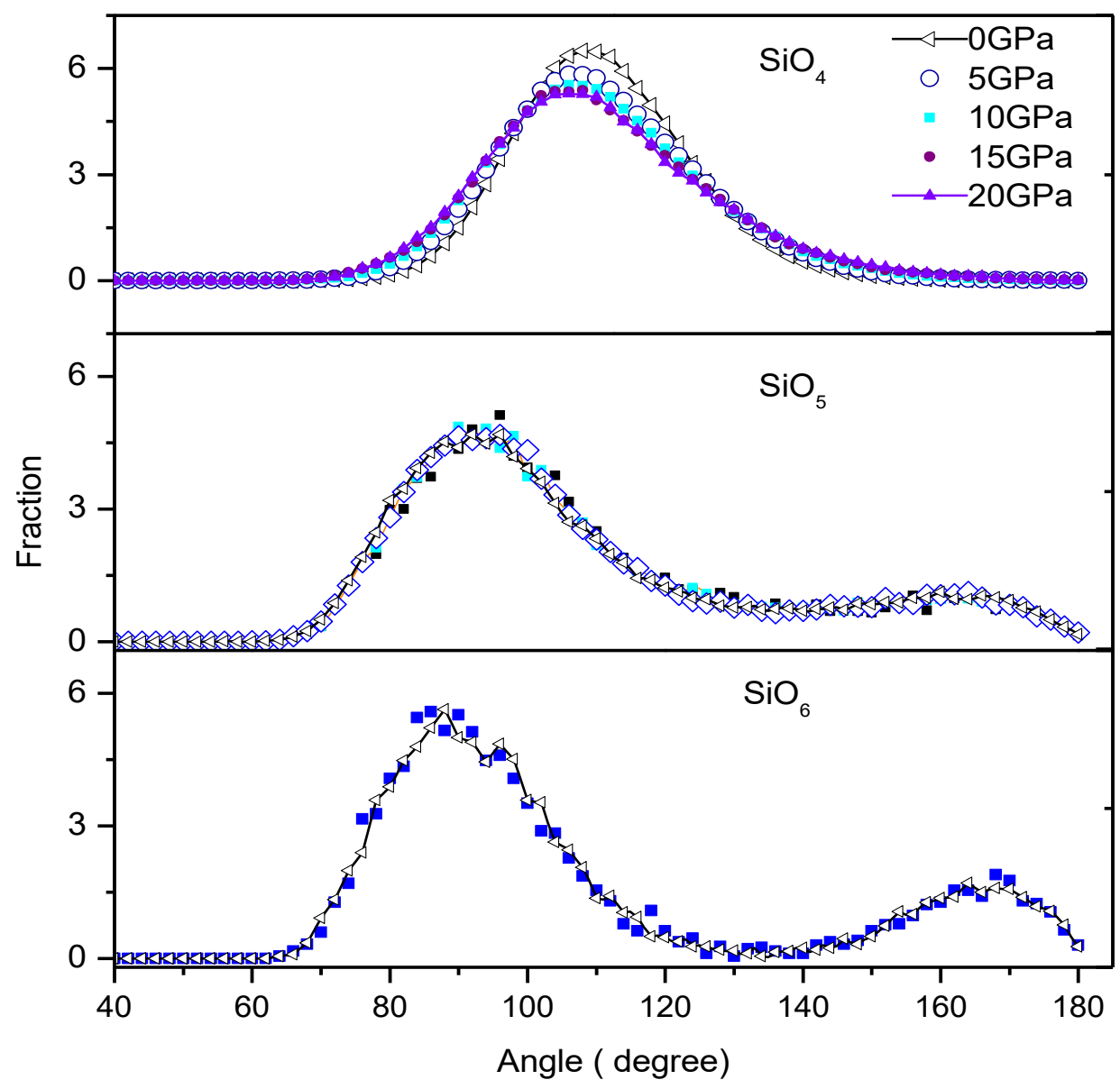

Fig. 3. Partial bond angle distributions for structural units $\mathrm{SiO}_{\mathrm{x}}(\mathrm{x}=4,5,6)$ at different pressures. 
To investigate the short-range order, the $\mathrm{O}-\mathrm{Si}-\mathrm{O}$ bond angle and $\mathrm{Si}-\mathrm{O}$ bond length distribution in the coordination units $\mathrm{SiO}_{\mathrm{x}}$ (main coordination units) have been calculated. Figure 3 presents the partial bond angle distributions for structural units $\mathrm{SiO}_{\mathrm{x}}(\mathrm{x}=4,5,6)$ at different pressures. The results show that the partial $\mathrm{O}-\mathrm{Si}-\mathrm{O}$ bond angle distribution in each kind of coordination unit $\mathrm{SiO}_{\mathrm{x}}$ is almost the same for different pressure. This means that the distribution of partial bond angle in $\mathrm{SiO}_{4}, \mathrm{SiO}_{5}$, and $\mathrm{SiO}_{6}$ units is not dependent on pressure. Here angle distribution in $\mathrm{SiO}_{4}$ units has a form of Gauss function and a pronounced peak at $105^{\circ}$ and $90^{\circ}$ with $\mathrm{SiO}_{5}$ unit. This result is similar to experimental and other simulated data reported in $[19,21]$ and indicates a slightly distorted tetrahedron with a Si atom at the center and four $\mathrm{O}$ atoms at the vertices. In the case of angle distribution in $\mathrm{SiO}_{6}$, there are two peaks: a main peak locates at $90^{\circ}$ and small one at $165^{\circ}$. The partial $\mathrm{Si}-\mathrm{O}$ bond length distribution in coordination units $\mathrm{SiO}_{4}, \mathrm{SiO}_{5}$, and $\mathrm{SiO}_{6}$ is shown in Fig. 4. It shows that The $\mathrm{Si}-\mathrm{O}$ bond length distributions in $\mathrm{SiO}_{4}$, $\mathrm{SiO}_{5}$, and $\mathrm{SiO}_{6}$ units have peaks at 1.62, 1.64, and $1.74 \AA$, respectively. This structural characteristic has been explained via the Coulomb repulsive force between anion and anion $\left(\mathrm{O}^{-2}\right.$ and $\mathrm{O}^{-2}$ ions).The force in $\mathrm{SiO}_{5}$ and $\mathrm{SiO}_{6}$ units is much stronger than the one in $\mathrm{SiO}_{4}$. This leads an increase of $\mathrm{Si}-\mathrm{O}$ bond length in $\mathrm{SiO}_{5}$ and $\mathrm{SiO}_{6}$.

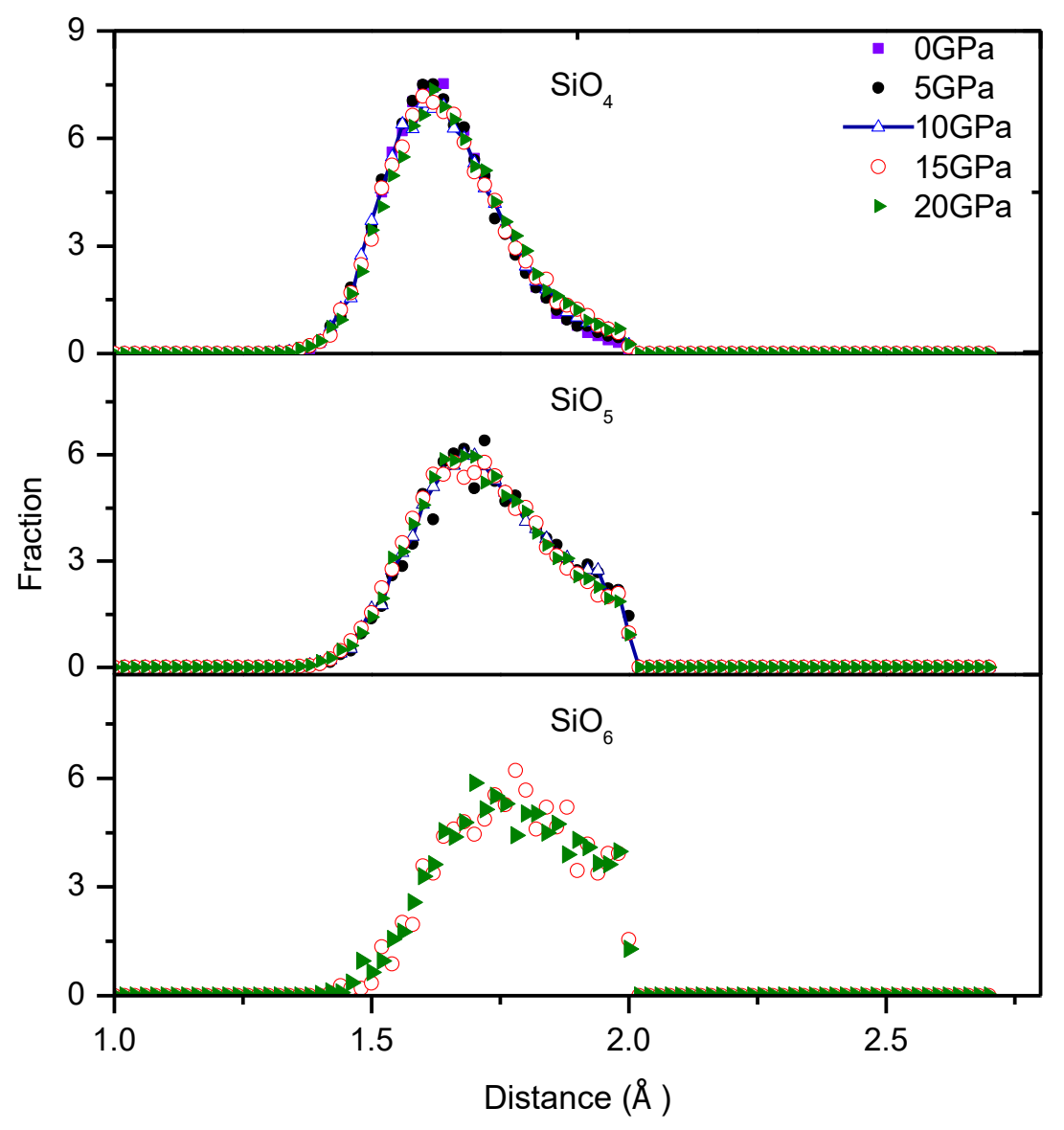

Fig 4. The $\mathrm{Si}-\mathrm{O}$ bond length distributions for structural units $\mathrm{SiO}_{\mathrm{x}}(\mathrm{x}=4,5,6)$ at different pressures. 


\section{The diffusion process in silica under compression}

The diffusion coefficient of particles is determined from the mean square displacement (MSD) of atom via Einstein equation

$$
D=\lim _{t \rightarrow \infty} \frac{<R(t)^{2}>}{6 t}
$$

Where $t=N . T_{M D} ; N$ is number of MD steps; $T_{M D}$ is MD steps and equal $1.0 \mathrm{fs}$, The Fig 5 describes the time dependence of Silicon (or Oxygen) MSD under different pressure. One can see that the data fall on straight- line plot. We have calculated coefficient diffusion from the slope of these lines.
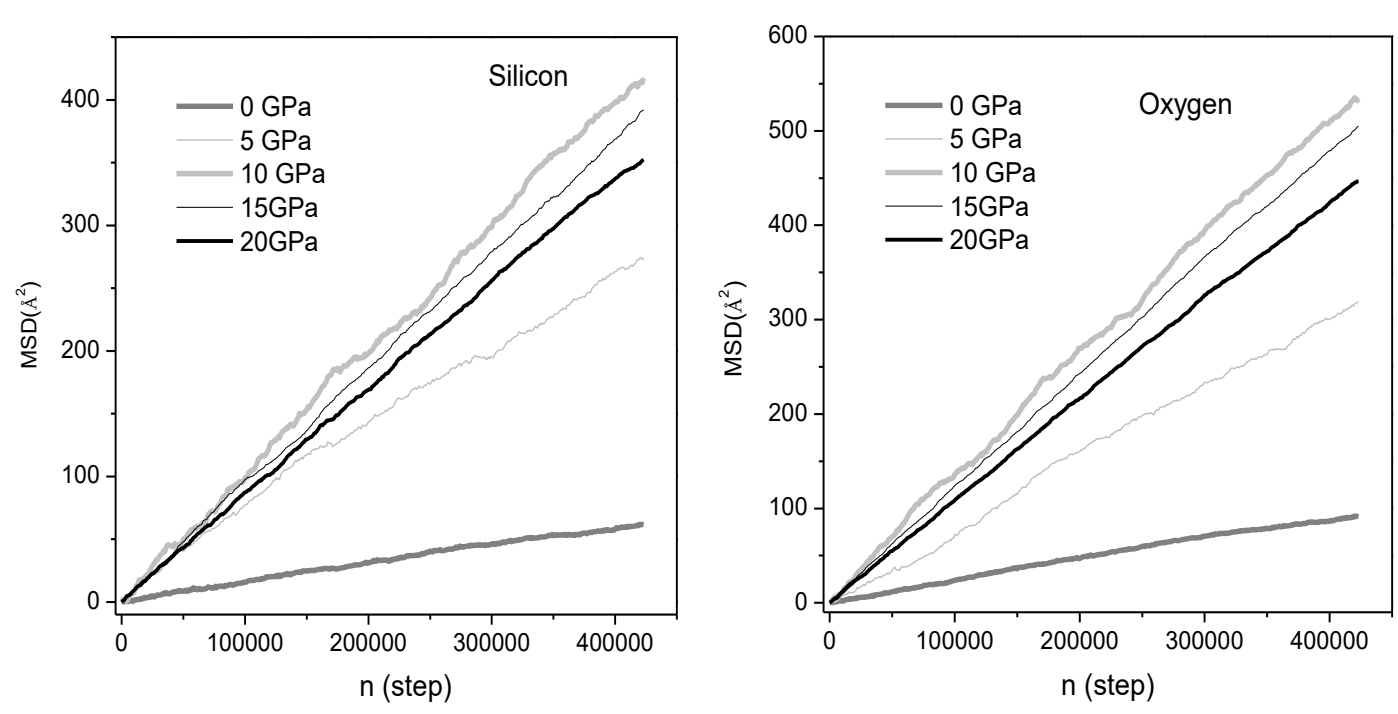

Fig 5. The step dependence of mean square displacement in silica liquid at different pressure.

The anomalous diffusion is observed via Fig.6. It can be seen that there is a monotonous growth of coefficient diffusion with upon compression and a maximum point near $\mathrm{P}=10 \mathrm{GPa}$ that consistent with previous simulation [22-23]. The self-diffusion coefficient increases with increasing pressure $(0 \div 10$ $\mathrm{GPa}$ ) meanwhile the self-diffusion coefficient decreases with pressure at $10 \div 20 \mathrm{GPa}$. We find that the change in diffusion mechanism between low and high-pressure in silica liquid. The change in diffusion mechanism can be explained by that upon compression the $\mathrm{SiO}_{4}$ unit transforms to $\mathrm{SiO}_{5}$ and $\mathrm{SiO}_{6}$ where the $\mathrm{Si}-\mathrm{O}$ bond is much weaker. This leads an increase in mobility of $\mathrm{Si}$ and $\mathrm{O}$ atoms. On the other hand the liquid becomes much denser under pressure and diffusion process more difficult. One can see that the bond weakening and the liquid densification affect the diffusion coefficient in opposite directions. At the low-pressure configuration, the influence of the bond weakening of $\mathrm{Si}$, O in the newly formed structure units $\mathrm{SiO}_{5}$ and $\mathrm{SiO}_{6}$ is larger than that of liquid densification. Therefore, the coefficient diffusion increases. However, at the high-pressure configuration, rate of transition from $\mathrm{SiO}_{4}$ to $\mathrm{SiO}_{5}$ or $\mathrm{SiO}_{6}$ decreases and effect of liquid densification predominate. The coefficient diffusion decreases and Fig.6 has a maximum point. 


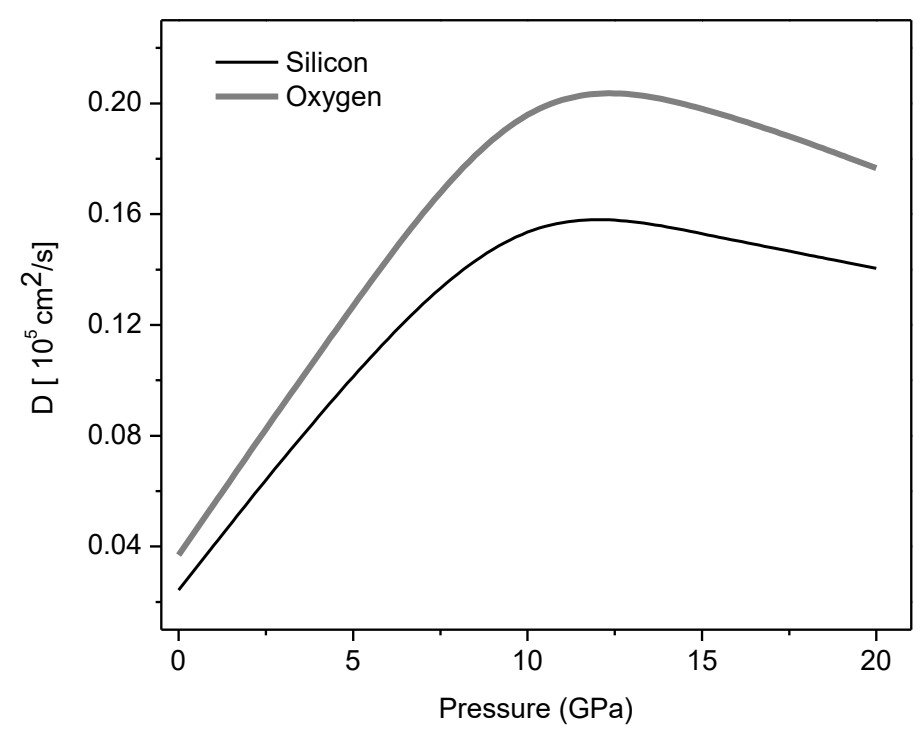

Fig 6. The pressure dependence of diffusion coefficient of silicon and oxygen in silica liquid.

\section{Conclusion}

In this work, microstructure and dynamic properties of large model of silica liquid at pressures ranging from 0 to $20 \mathrm{GPa}$ were investigated in detail. Results reveal that the structure of $\mathrm{SiO}_{2}$ liquid consists of structural units $\mathrm{SiO}_{\mathrm{x}}(\mathrm{x}=4,5,6)$ and $\mathrm{OSi}_{\mathrm{y}}(\mathrm{y}=2,3)$. At ambient, the number of $\mathrm{SiO}_{4}$ and $\mathrm{OSi}_{2}$ unit is domain. Upon compression, the fraction of $\mathrm{SiO}_{5}$ and $\mathrm{SiO}_{6}$ increases meanwhile fraction of $\mathrm{OSi}_{3}$ and $\mathrm{OSi}_{2}$ also increases. The distribution of partial bond angle and bond length in $\mathrm{SiO}_{4}, \mathrm{SiO}_{5}$, and $\mathrm{SiO}_{6}$ units is not dependent on pressure. The cation-cation, anion-anion Coulomb repulsion is the origin of the increase of the mean Si-O bond length under compression. Furthermore, the diffusion in silica liquid shows anomalous behavior and the origin of anomalous diffusivity is due to the change of $\mathrm{SiO}_{5}$ and $\mathrm{SiO}_{6}$ concentration under compression. These results are similar to our previous simulation. These demonstrate that the model silica liquid consisting of 2000 atoms was good enough for us to study structural properties and diffusion. However, the large model will help us further study the original of dynamical heterogeneity that is difficult with the small model (2000 atoms).

\section{Acknowledgement}

The authors are grateful for support by the Ministry-level projects (grant No B2018-BKA-57)

\section{References}

[1] Gergely Molnár, Patrick Ganster, Anne Tanguy, Physical review E 95, 043001 (2017)

[2] M. M. Smedskjaer,Frontier Mater, 1(23),1,(2014)

[3] B. Hehlen and D. R. Neuville. J Phys Chem B. 119 (10), 4093,( 2015)

[4] T. Kawasaki, H. Tanaka, J. Phys.: Condens. Matter 22, 232102 (2010).

[5] G. Calas, L. Galoisy, L. Cormier, G. Ferlat, G. Lelong,Procedia Materials Science 7, 23 (2014)

[6] J. Badro, D. M. Teter, R. T. Downs, P. Gillet, R. J. Hemley, and J.L. Barrat, Phys. Rev. B 56, 5797 (1997) 
[7] C. Weigel, L. Cormier, G. Calas, L. Galoisy, D.T. Bowron, Phys. Rev. B 78, 064202 (2008)

[8] H. Jabraoui, Y.Vaills, A. Hasnaoui, M. Badawi and S. Ouaskit, J. Phys. Chem. B 120, 13193 (2016).

[9] T. K. Bechgaard eltal., J. Non-Cryst. Solids 441, 49 (2016)

[10] S. K. Baggain, D. B. Ghosh, B. B. Karki, Phys. Chem. Min. 42, 393 (2015).

[11] A. W.Cooper, P. Harrowell, and H. Fynewever, Phys. Rev. Lett 93, 135701 (2004).

[12] J.R. Allwardt, J.F. Stebbins, B.C. Schmidt, D.J. Frost, A.C. Withers, M.M. Hirschmann, Am. Mineral. 90,1218 (2005)

[13] M. Bauchy, M. Micoulaut, Physical review B 83, 184118 (2011)

[14] H. Jabraoui, E.M. Achhal, A. Hasnaoui, J.-L. Garden,Y.Vaills, S. Ouaskit, J.Non-Cryst-Solid 448,16(2016)

[15] S.K. Lee, G.D. Cody, Y. Fei, B.O. Mysen, Chem. Geol. 229,162 (2006).

[16] I. Jackson, Phys. Earth Planet. Inter. 1, 218 (1976)

[17] B.T. Poe etal., Science 276, 1245 (1997)

[18] M. Scott Shell, G.D.Pablo, Z.P. Athanassios, Phys. Rev.E 66, 011202 (2002)

[19] D.I. Grimley, A.C. Wright, R.N. Sinclair, J. Non-Cryst. Solids 119, 49 (1990).

[20] Mozzi R L and Warren B E, J. Appl. Crystallogr. 2164 (1969)

[21] Bauchy M, J Chem Phys. 141, 024507 (2014)

[22] T. Morishita, Phys. Rev. E 72, 021201 (2005)

[23] P.K. Hung, N.T.T. Ha, N.V. Hong, J. Non-Cryst. Solids 358, 1649 (2012) 